Please cite this paper as follows

Eduard Bullich-Massagué, Mònica Aragüés-Peñalba, Andreas Sumper, Oriol Boix-Aragones, Active power control in a hybrid PV-storage power plant for frequency support, Solar Energy, Volume 144, 1 March 2017, Pages 49-62, ISSN 0038-092x, http://dx.doi.org/10.1016/j.solener.2016.12.033. 


\title{
1 Active Power Control in a Hybrid PV-Storage Power Plant for Frequency Support
}

\author{
3 Eduard Bullich-Massaguéa,*, Mònica Aragüés-Peñalba ${ }^{\mathrm{a}}$, Andreas Sumper ${ }^{\mathrm{a}}$, \\ 5 \\ 6 \\ Oriol Boix-Aragones ${ }^{\mathrm{a}}$ \\ ${ }^{a}$ Centre d'Innovació Tecnològica en Convertidors Estàtics i Accionaments \\ (CITCEA-UPC), Departament d'Enginyeria Elèctrica, Universitat Politècnica de \\ Catalunya ETS d'Enginyeria Industrial de Barcelona, Avinguda Diagonal, 647, Pl. 2, \\ 08028 Barcelona, Spain
}

\begin{abstract}
The recent increase of intermittent power generation plants connected to the electric power grids may stress the operation of power systems. So, grid codes started considering these power plants should contribute to the grid support functions. Recently, a power ramp rate limitation is being included in several grid codes, which is a challenge for photovoltaic installations due to the lack of inertia. This paper presents a method to deal with the main grid code requirements considering a PV plant with an energy storage device, where a strict two-second time window ramp rate restriction is applied. A direct ramp rate control strategy is used, which includes a dynamic SOC control and battery support functionality for active power setpoint compliance. The control strategy is validated by simulations.

Keywords: $\mathrm{PV}$ plant, ramp rate, storage, control
\end{abstract}

\section{Nomenclature}

*Corresponding author

Email address: eduard.bullich@citcea.upc.edu (Eduard Bullich-Massagué) 


\begin{tabular}{|c|c|}
\hline$P_{p v-m e a s}$ & $\begin{array}{l}\text { Measured PV power. There is a communication } \\
\text { delay between } P_{p v} \text { and } P_{p v-\text { meas }}\end{array}$ \\
\hline$P_{b a t-m e a s}$ & $\begin{array}{l}\text { Measured battery power. There is a communication } \\
\text { delay between } P_{b a t} \text { and } P_{b a t-m e a s}\end{array}$ \\
\hline$P_{p c c-m e a s}$ & $\begin{array}{l}\text { Measured active power at the point of common coupling. } \\
\text { There is a communication delay between } P_{p c c} \text { and } P_{p c c-m e a s}\end{array}$ \\
\hline$P_{T S O}$ & Power setpoint at the PCC (sent by TSO) \\
\hline$P_{p v}^{*}$ & $\begin{array}{l}\text { PV plant setpoint. Aggregated PV active power setpoint } \\
\text { of PV arrays (excluding the battery) }\end{array}$ \\
\hline$P_{\text {bat }}^{*}$ & Battery active power setpoint \\
\hline$P_{t o t}$ & Output of the PV PI controller \\
\hline$\alpha$ & PV inverter setpoint in p.u. $\left(\alpha=\frac{P_{\text {tot }}}{P_{\text {plant }}}\right)$ \\
\hline$P_{\text {nom }, i}$ & Nominal power of the inverter $i$ \\
\hline & Active power setpoint of the PV inverter $i$ \\
\hline$P_{p v-r}^{*}$ & $\begin{array}{l}\text { During curtailment event, PV plant setpoint } \\
\text { after applying the ramp rate limitation }\end{array}$ \\
\hline$P_{p c c-f i l t}$ & Filtered $P_{p c c-\text { meas }}$. Used in the MPP mode \\
\hline$P_{p v-a v}$ & Available PV power. Maximum PV power \\
\hline$P_{\text {plant }}$ & $\begin{array}{l}\text { Nominal power of the PV plant } \\
\text { that the PV plant can generate }\end{array}$ \\
\hline$P_{b a t-n o m}$ & Nominal power of the battery \\
\hline$P_{b a t-\max }$ & Maximum $(>0)$ battery power \\
\hline$P_{b a t-\min }$ & Minimum $(<0)$ battery power \\
\hline$C_{\text {bat-nom }}$ & Nominal capacity of the battery \\
\hline$S O C$ & Battery State Of Charge \\
\hline$S O C_{\text {meas }}$ & $\begin{array}{l}\text { Measured SOC. There is a communication } \\
\text { delay between } S O C \text { and } S O C_{\text {meas }}\end{array}$ \\
\hline$S O C^{*}$ & SOC setpoint \\
\hline$\eta_{\text {bat }}$ & Battery efficiency \\
\hline$\tau_{\text {bat }}$ & Response time of the battery \\
\hline$\tau_{p v}$ & Response time of the PV inverters \\
\hline$\tau_{\text {com }}$ & Communication delay \\
\hline$\tau_{\text {meas }}$ & $P_{p c c-m e a s}$ filter time constant \\
\hline$T_{d}$ & Delay added by the $P_{p c c-m e a s}$ filter \\
\hline$f_{\text {meas }}$ & Measured grid frequency \\
\hline
\end{tabular}




$P_{D}$
$P_{\text {min }}, f_{\text {min }}$
$f_{1}, f_{2}, f_{n}, f_{3}, f_{4}, f_{\text {max }}$
$R R_{\text {max }}$
$R R_{\text {min }}$
$T_{w}$
$\Delta P_{\text {max }}$
$\Delta P_{\text {mim }}$
$T_{s}$
$K_{p-p v}$
$K_{i-p v}$
$K_{w-p v}$
TSO
PV
LSPVPPs
ESS
PCC
PPC
MPP
FACTS
DC
NREL

Active power of the dead-band of the droop curve Parameters defining the droop curve Parameters defining the droop curve Maximum up-ramp rate $\left[\frac{\% P_{\text {plant }}}{\text { minute }}\right]\left(R R_{\max }>0\right)$ Minimum down-ramp rate $\left[\frac{\% P_{\text {plant }}}{\text { minute }}\right]\left(R R_{\text {min }}<0\right)$ Time window for the ramp rate calculation Maximum $\triangle P$ at the PCC between $t$ and $t+T_{w}$ Minimum $\Delta P$ at the PCC between $t$ and $t+T_{w}$ Sample time of the power plant controller Proportional constant of the PI of the PV controller Integral constant of the PI of the PV controller Anti wind-up constant of the PI of the PV controller Transmission System Operator PhotoVoltaic Large Scale PV Power Plants Energy Storage System Point of Common Coupling. Interconnection point between the PV plant and the external grid Power Plant Control Maximum Power Point Flexible AC Transmission System Direct Current National Renewable Energy Laboratory

\section{Introduction}

The installation of renewable energies in the electricity sector have experienced a rapid growth during last years [1, 2], being wind and photovoltaic (PV) power the technologies with the major growth in Europe [3]. Currently, the participation of wind and PV power on the energy mix is large enough to require these power plants to provide grid support functions. In this direction, grid codes are being updated forcing these power plants to provide grid support [4-8]. One of the main issues of wind and PV power plants is that they act as intermittent power generation plants that can affect the grid stability. So, grid codes have recently included the need to mitigate the rapid active power fluctuations [5, 7]. Despite this requirement is not explained in detail, there are some proposals suggesting how to evaluate its fulfillment [9]. 
In [10], a power plant controller capable to fulfill most of the grid codes is presented. The controller, which manages the active and reactive power of the PV plant as well as capacitor banks and FACTS devices, is validated in a real 9.4 MW PV plant in Romania. As energy storage devices are not considered, the ramp rate limitation is only applied when curtailment events occur and from the curtailment to the maximum power point transition. Some papers propose different strategies to mitigate PV power fluctuations [11-15], which are based on integrating energy storage systems in the PV power plant. In [11], two ramp rate control strategies are developed depending on the cycle-life of storage technology. For low cycle-life technologies, it is intended to maintain the state of charge (SOC) between 40-60\%, where the storage device operates on stand-by condition. In contrast, for long cycle-life technologies, the state of charge follows the PV plant relative output. The study performed in [12] proposes a method to limit the power fluctuations of a PV inverter. The strategy is developed for ramping and post-ramping event to recover the SOC. In this case, the storage device is connected to the DC link of the PV inverter. However, this topology is not reasonable for a power plant with more than 1 inverter as it is well-known that PV power fluctuations reduce as the plant size increases [16]. So, a centralized energy storage seems to be more reasonable. In [13], a ramp rate control strategy based on irradiance forecasting is presented. Thanks to the irradiance prediction, the controller anticipates the ramp events and the battery nominal power is reduced. This strategy does not consider the SOC of the storage device. In the work presented in [14], a ramp rate control for PV installation in microgrids is proposed. Furthermore, it explains the limitations of the traditional moving average control strategy. This traditional strategy does not provide direct ramp rate control and the storage system operates continuously even if the ramp rate is between the up-down limits. In contrast, the energy flow (in-out) through the battery is much lower with a direct ramp rate control due to the fact that the battery does not operate if it is not strictly necessary. In [15], it is said thatdelay in power measurement and transmission may cause significant error which may not only generate a less smooth output but also may act in reverse direction and add even more fluctuation to the aggregate output. However, the effect of the delays are not studied in [15].

The studies performed in [11-14] do not explain how to control the PV plant during curtailments and frequency droop events. In general, when the ramp rate is controlled directly, these studies do not consider communication 
delays nor plant dynamics. The previous cited grid codes require additional modes of operation that affect the PV active power output as power curtailment or frequency droop. The utilization of energy storage systems under other operation modes can help to improve the performance (e.g. during a power curtailment, a SOC control can be performed or the battery can help to reach the setpoint in case of a lack of available PV power). To the best of our knowledge, there are no previous studies suggesting how to coordinate the utilization of the storage systems with the PV inverters during curtailment or frequency droop events.

This paper proposes a practical method to fulfill the grid code requirements including the ramp rate limitation, the power curtailment and the frequency droop considering a hybrid PV-ESS power plant. For the ramp rate limitation, the direct ramp rate control strategy explained later is used. The results are validated by simulations, where communication delays and a simplified model of plant dynamics are taken into account. The effect of the delays and plant dynamics are mitigated thanks to the proposed controller. Forecasting is not considered in this work.

\section{Hybrid PV-Storage power plant model}

\subsection{Overview of the Hybrid PV-Storage Power Plant}

Figure 1 depicts a general scheme of a hybrid PV-battery power plant with ring configuration. This topology (e.g. Vanju-Mare 9.4 MW PV plant, Romania) as well as tree configuration are the most used in large-scale PV plants. In addition, a centralized storage for ramp rate compliance has been added. The reason for using centralized storage is that as the PV plant size increases, the relative power fluctuations diminish [17]. So, when it is desired to limit the fluctuations at the point of common coupling (PCC), lower storage features are required than when considering a strategy based on limiting the power fluctuations at the PV inverters output.

A central power plant controller (PPC) coordinates all PV inverters together with the ancillary devices to achieve the desired setpoints at the PCC. This controller sends active and reactive power setpoints to PV inverters, storage and FACTS devices as well as connection/disconnection orders to capacitor banks. All of these devices have local controls to follow the PPC commands. In [10] there is a detailed description of the PPC operation in PV plants without storage. This paper enhances the PPC performance considering energy storage devices. 


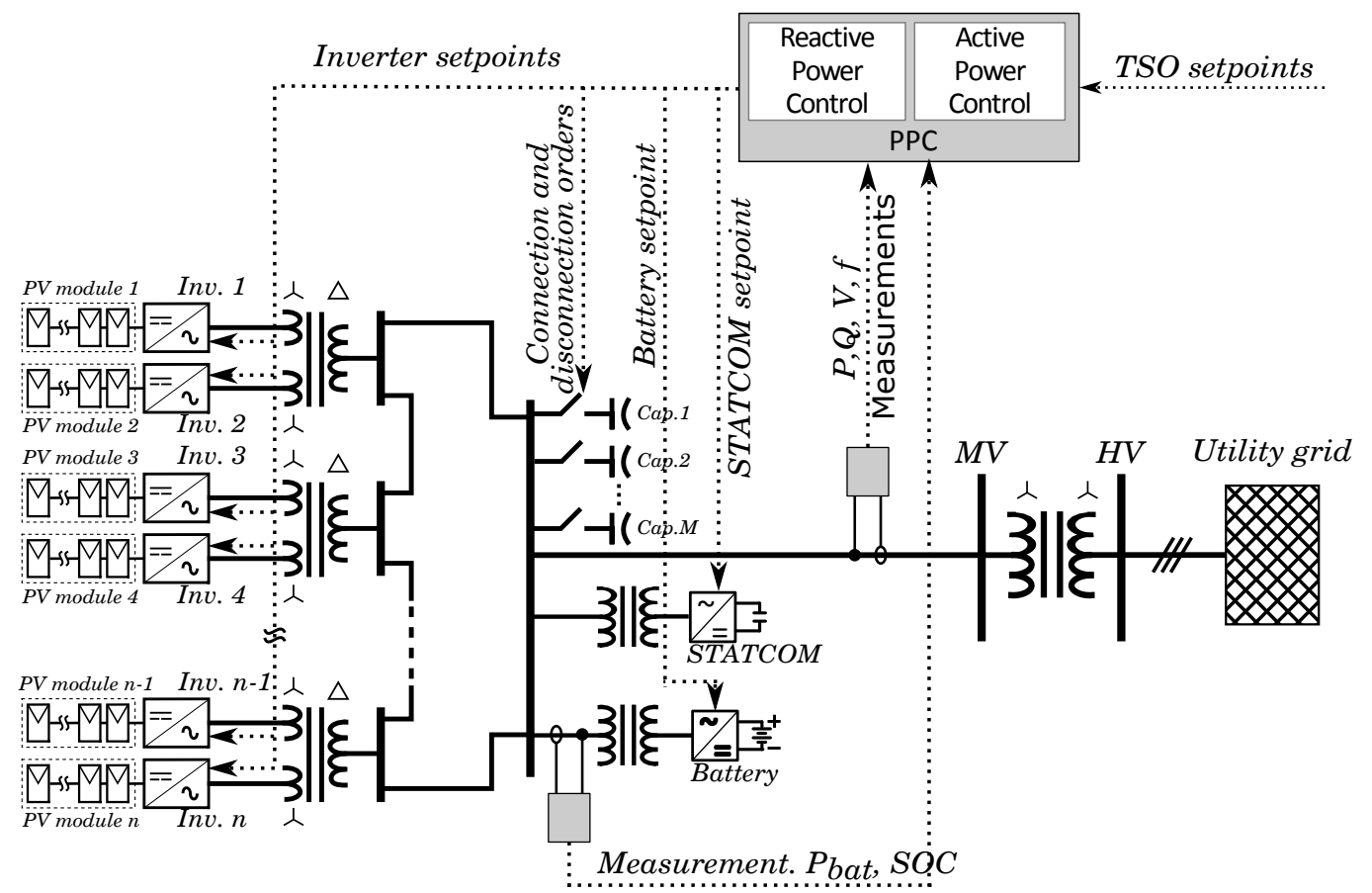

Figure 1: General scheme of a hybrid PV-battery power plant

\subsection{Power Plant Model}

In this paper a simplified plant model is used. As only the active power is studied, the model considers an equivalent PV generator and a battery energy storage. The equivalent PV generator represents the PV arrays plus the PV inverters. Based on the observation of SMA PV inverter dynamics, it is modelled as a first order function (Figure 2(a)), where the input is the PV inverter setpoint $\alpha$ in per unit system. If we consider several PV inverters, each PV inverter $i$ computes its local setpoint according to (1), where $P_{n o m, i}$ is the nominal power of the inverter $i$. As we consider an aggregated PV inverter, $P_{n o m, i}=P_{\text {plant }}$. The output is the PV power $P_{p v}$, which is limited to a power profile $\left(P_{p v-a v}\right.$, available PV power obtained from real measurements).

$$
P_{p v-s e t, i}^{*}=\alpha \cdot P_{n o m, i}
$$

The storage model represents a battery and its associated inverter and is also modelled as a first order function to simulate its dynamics. The 
output of the first order function is saturated according to (2) and (3). The saturation prevents the model to inject power $(P>0)$ if the $S O C=0$ and to store power $(P<0)$ if $S O C=1$ and limits the maximum power to be injected or consumed to its nominal power $P_{b a t-n o m}$. The SOC of the battery is calculated taking into account its efficiency $\eta_{b a t}$ (see Figure 2(b)).

$$
\begin{gathered}
P_{b a t-\text { max }}= \begin{cases}P_{b a t-n o m} & \text { if } S O C>0 \\
0 & \text { if } S O C=0\end{cases} \\
P_{b a t-\text { min }}= \begin{cases}-P_{b a t-n o m} & \text { if } S O C<1 \\
0 & \text { if } S O C=1\end{cases}
\end{gathered}
$$

The model also takes into account communications delays, $\tau_{\text {com }}$ (see Figure 2(c)). Frequency deviations can be simulated by changing $f_{\text {meas }}$ in order to test the frequency droop operation. Figure 2(c) depicts the complete model including the power plant controller.

\section{Control requirements}

The basic grid code requirements for frequency support actions are those related to the active power and can be summarized in:

i) Active power curtailment: the Transmission System Operator (TSO) sends an active power setpoint to be injected at the PCC.

ii) Frequency regulation by droop curve: the TSO specifies a curve which predefines an increase or decrease of the active power delivered at PCC as a function of the measured frequency. Figure 3(a) depicts the droop curve according to South African grid code [5]. The application of this curve is not explained in detail in the grid codes. According to the author's experience in real PV plants, we consider the following procedure for applying the droop curve:

- If the power plant is operating at the MPP, $P_{D}$ is set to the active power measurement at the PCC as soon as a frequency deviation exceeds $f_{4}$. This setpoint $P_{D}$ remains constant until the frequency goes back to the dead band. In the case of down frequency event (the frequency is below $\left.f_{2}\right) P_{D}$ is set to the $P_{p v-\text { meas }}(t)$. The grid code specifies that $P_{p v-a v} \geq$ $1.03 \cdot P_{D}$. Due to the fact that forecast is not considered, the energy storage must reserve a minimum delivery power of $0.03 \cdot P_{\text {pcc-meas }}$. 


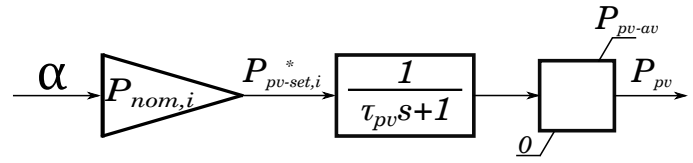

(a) Simplified PV generator model

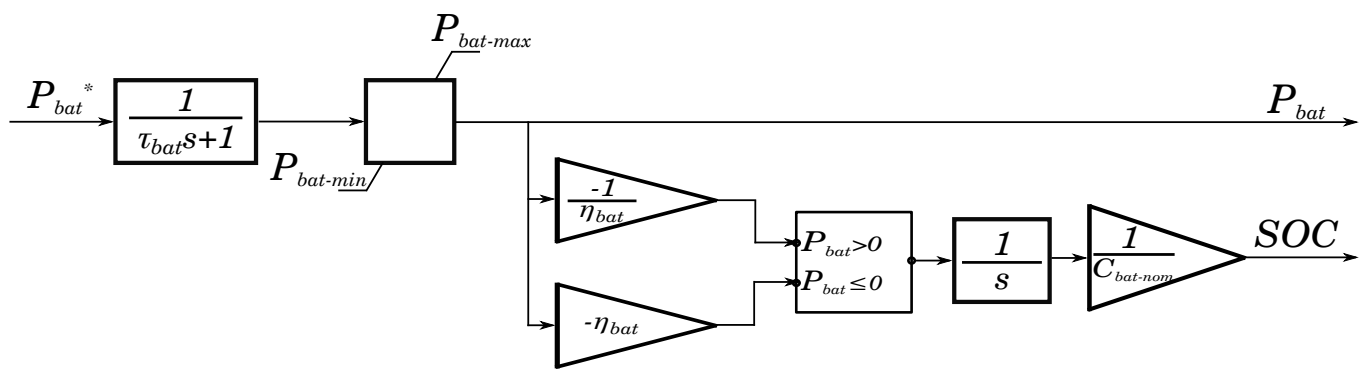

(b) Simplified Battery model

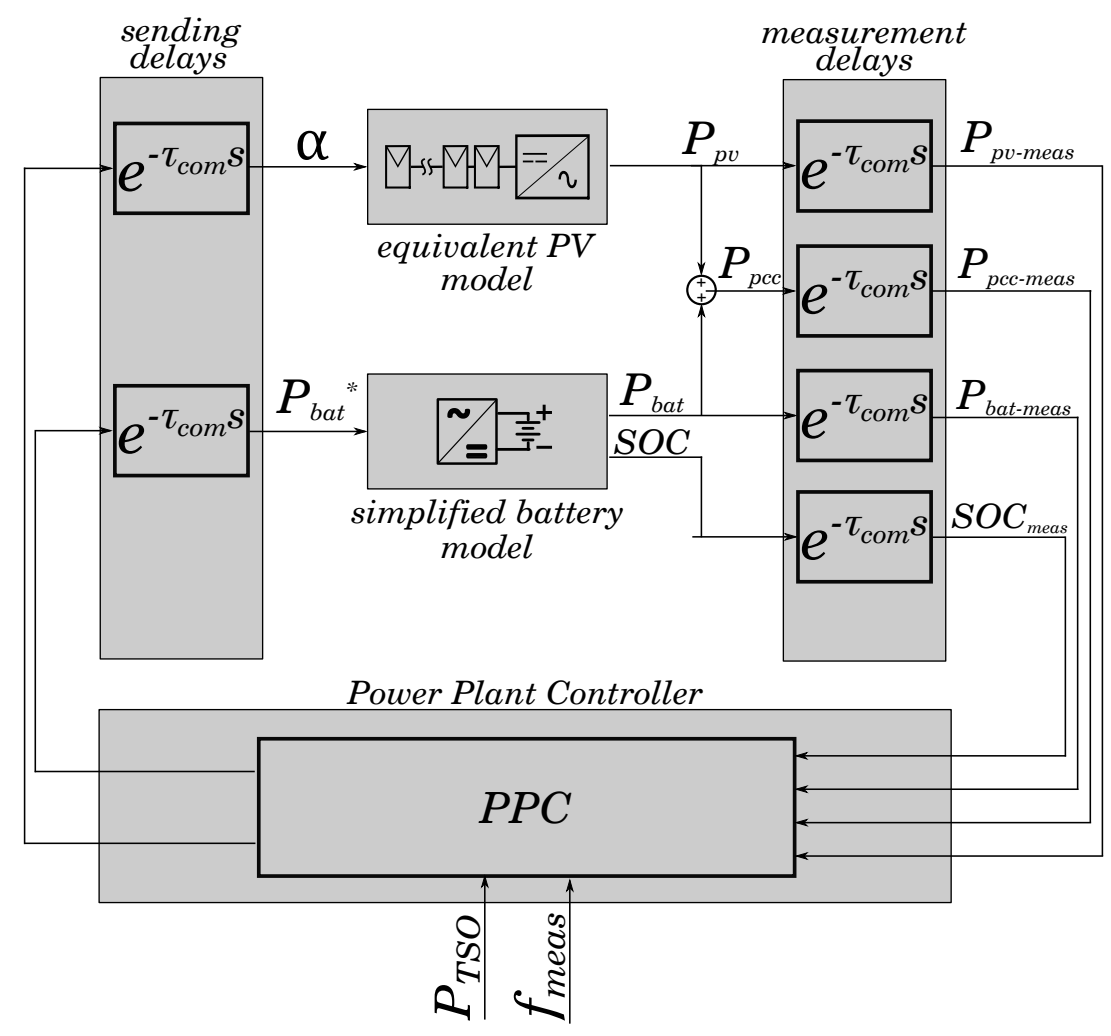

(c) Model of the hybrid PV-storage power plant

Figure 2: Detail of the hybrid PV-storage power plant 
Figure 3(b) shows an application example. Until time $t_{1}$ the frequency is at its nominal value and the plant is operating at the MPP. At time $t_{1}$ the frequency increases to $F$. At this time, $P_{D}$ is set to the measured active power at PCC and remains constant and the new setpoint is computed according to the droop curve.

- If the TSO performs a curtailment, $P_{D}$ is the active power setpoint taking into account the ramp rate limitation $\left(P_{D}=P_{p v-r}^{*}\right)$. Once the curtailment ends, $P_{D}$ remains constant until the frequency goes back to the dead band.

Figure 3(c) shows an application example. First, TSO sets a power curtailment (red line). The curtailment is limited by a ramp rate. So, the $P_{p c c}$ follows the ramp limitation. At $t_{1}$ a frequency deviation occurs and $P_{D}$ is set to the ramp limited value. According to this value and the specified droop curve, the droop contribution is computed.

- The droop contribution is not limited by a ramp rate.

iii) Ramp rate control: any variation of active power must not exceed a certain level of ramp rate. This level is usually set to $\frac{0.1 \cdot P_{\text {plant }}}{\text { minute }}$. Where $P_{\text {plant }}$ is the nominal active power of the PV plant (e.g. in Puerto Rico and Romania [18]). This requirement is not applied to the droop curve contribution.

\section{Control solution}

This section presents the control solution. The objective is to fulfill the grid code requirements regarding to the active power control actions.

\subsection{Controller structure}

The controller can be divided into three steps as shown in Figure 4(a): reference computation, PV controller and PV dispatch. The first step (reference computation) computes the battery and PV setpoints taking into account the grid code requirements and the SOC of the battery. The battery setpoint is sent directly to the battery inverter and will be achieved thanks to the inverter local controller. On the other hand, the PV setpoint can not be sent directly to PV inverters. It is due to the fact that, despite being simulated as an aggregated PV inverter, LSPVPPs consists of more than 1 PV inverter having different available power. So, the PV controller (proportional-integral 


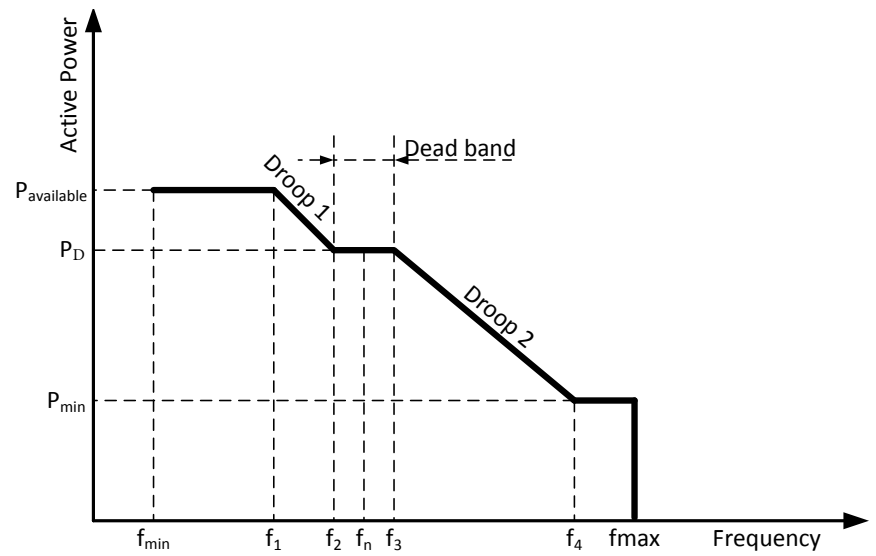

(a) Generic frequency-active power (f-P) droop curve according to grid codes

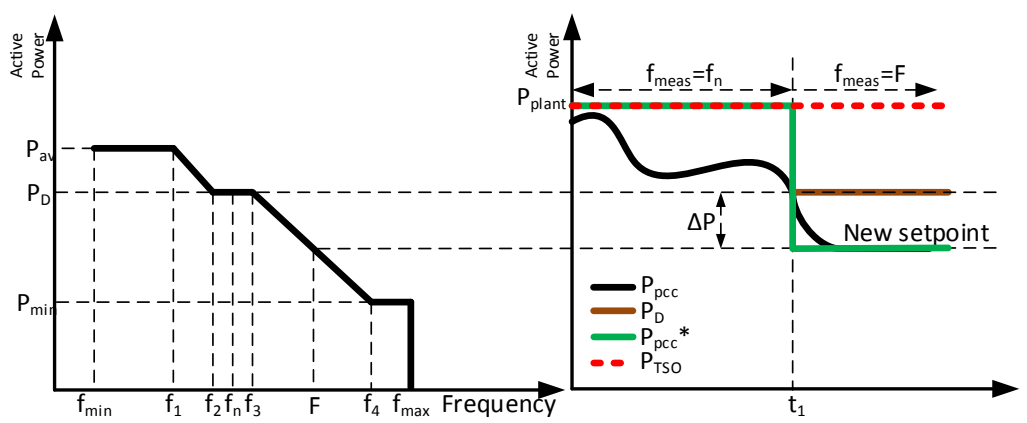

(b) Droop application under MPP mode

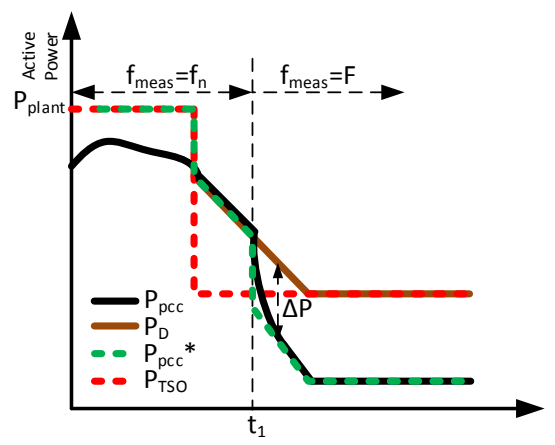

(c) Droop application under curtailment mode

Figure 3: Frequency droop curve and its application 
controller) computes $P_{t o t}$, which is a corrected PV power setpoint that compensates possible lack of available active power from some PV inverters. Then, $P_{t o t}$ must be distributed among all PV inverters. It is performed at the PV dispatch step. Sending the setpoints to the PV inverters in per unit (p.u.) system, only one signal $\alpha$ must be computed. So, $\alpha$ is computed as (4). Then, each inverter $i$ computes its local setpoint according to (1). Note that as the simulation model is an aggregated PV inverter, the PV inverter setpoint in $\mathrm{kW}$ will be $P_{t o t}$.

$$
\alpha=\frac{P_{\text {tot }}}{P_{\text {plant }}}
$$

\subsection{Reference computation}

The reference computation block is divided into MPP mode, curtailment mode and two frequency droop modes according to the droop operation explained before. The conditions to change the mode are shown in Figure 4(b). The flow chart shown later in Figure 7 depicts when the Mode selection is performed.

\subsubsection{MPP mode}

For the MPP mode, the basic concept is shown in Figure 5(a). There are different strategies in the literature to mitigate the power fluctuations. However, the strategies consisting on filtering the PV power measurement (e.g. the typical medium average technique) are not adequate for the purpose of this paper. This is due to the fact that grid codes require a ramp rate limitation while these strategies, despite being effective, do not have a direct control of the power ramp rate [14]. So, we perform a direct control of the ramp rate. This controller is corrective as it reacts once a ramp fault is detected. It means that for short periods ramp faults will occur, especially at the beginning of the event. The basic idea is that if the PV power at time $t$ does not exceed the ramp rate limitation, the reference power at the PCC will be $P_{\text {plant }}$ and the battery setpoint will be set to 0 . On the other hand, if the ramp rate is exceeded, the battery setpoint is calculated to bring the ramp rate to its limit. It can be expressed mathematically as (5). Obviously, $P_{b a t}^{*}(t)$ is constrained to its limits and if it is at the lower limit, the PV setpoint $P_{p v}^{*}(t)$ is modified (curtailed) to avoid exceeding the ramp rate (see equation (6) and Figure 5(c)). 


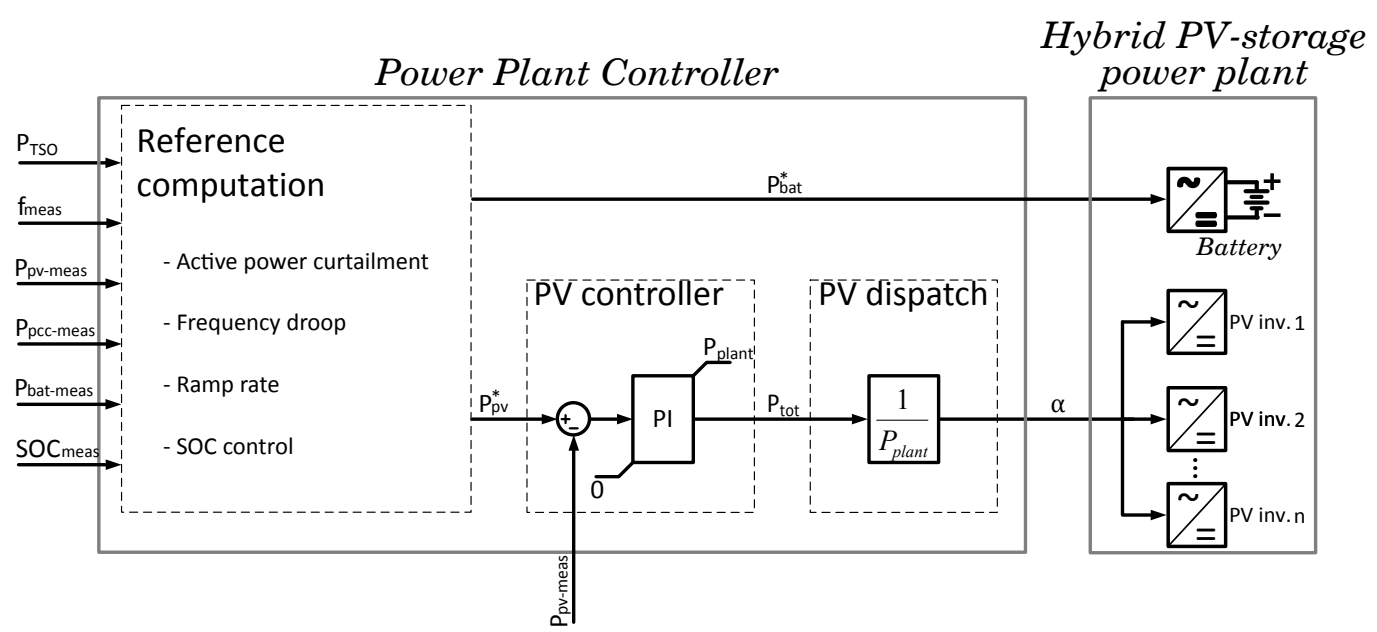

(a) Power plant controller structure

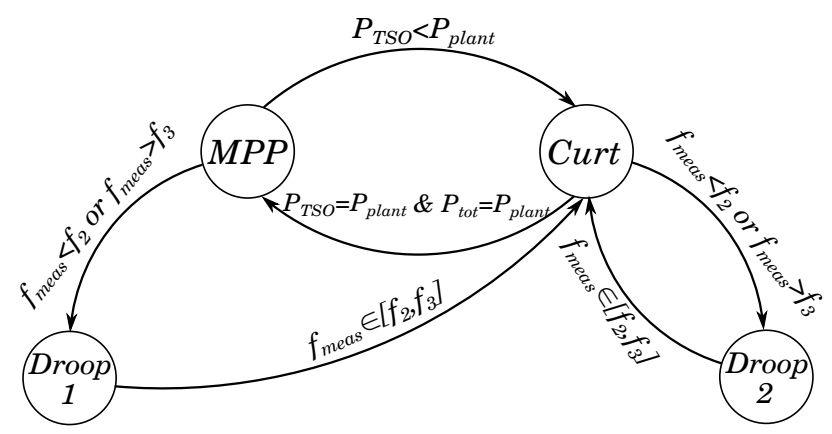

(b) Modes of the reference computation block. MPP: PCC setpoint $=$ rated power and the plant operates at the MPP. Droop 1: frequency deviation during MPP mode. Curtailment: TSO sets a PCC setpoint different than the rated power. Also applied for the transition from Droop 1 to MPP mode. Droop 2: frequency deviation during curtailment mode

Figure 4: Power plant controller

$P_{b a t}^{*}(t)= \begin{cases}P_{p c c-\text { meas }}\left(t-T_{w}\right)+\Delta P_{\text {max }}-P_{p v-\text { meas }}(t) & \text { if } P_{p v-\text { meas }}(t)-P_{p c c-\text { meas }}\left(t-T_{w}\right)>\Delta P_{\text {max }} \\ P_{p c c-m e a s}\left(t-T_{w}\right)+\Delta P_{\text {min }}-P_{p v-\text { meas }}(t) & \text { if } P_{p v-\text { meas }}(t)-P_{p c c-\text { meas }}\left(t-T_{w}\right)<\Delta P_{\text {min }} \\ 0 & \text { otherwise }\end{cases}$ 
215

$$
P_{p v}^{*}(t)= \begin{cases}P_{\text {pcc-meas }}\left(t-T_{w}\right)+\Delta P_{\text {max }}-P_{b a t-m e a s}(t) & \text { if } P_{b a t}^{*}=P_{b a t-m i n} \\ P_{\text {plant }} & \text { otherwise }\end{cases}
$$

$$
\text { Where } \Delta P_{\max }=R R_{\max } \cdot \frac{T_{w}}{60} \cdot \frac{P_{\text {plant }}}{100} \text { and } \Delta P_{\text {mim }}=R R_{\text {min }} \cdot \frac{T_{w}}{60} \cdot \frac{P_{\text {plant }}}{100} \text {. }
$$

Over this basic ramp rate limiter structure, some modifications are performed to improve the performance. The MPP mode applies the control block shown in Figures 5(b) and 5(c). To better understand how the control is performed, a flow diagram is included at section 5.3 (Figure 7). First of all, taking into account that the setpoints are not applied instantaneously due to the communication delays and the PV and battery time response, the response of the system (specially if $T_{w}$ is small) presents power oscillations during ramp events, where the main frequency is $\frac{1}{T_{w}}$. More detailed explanation is done in the Appendix A. Therefore, a filter to the measurement at the PCC is included. This filter adds a delay $T_{d}$ on the measurement that has to be taken into account. The maximum and minimum allowed active power variations $\Delta P_{\max }$ and $\Delta P_{\min }$ are calculated considering the filter delay as (7) and (8). Figure 6 shows an example of the performance with and without the filter. The filter proofs beneficial as it eliminates the ripple of the power generated when the battery is limiting the ramp rate. The other modification is the SOC control. With the scheme of Figure 5(b) [19], an offset to the battery setpoint is applied depending on the $S O C^{*}(t)$ and $S O C_{\text {meas }}(t)$. The setpoint $S O C^{*}(t)$ is computed following the $P_{p v-m e a s}(t)$, which means that the higher is the PV power measured, the higher will be the SOC setpoint. If the PV power is at high level, ramp-down events have more probability to occur, so we require the SOC to be at high level in order to be ready to discharge the battery. On the other hand, if the PV power is low, we will expect ramp-up events. So, the desired SOC will be at low levels to be able to charge when the ramp-up event occurs. The SOC ref calculation block computes the $S O C^{*}(t)$ as $(9)$. Note that the $S O C^{*}(t)$ is between 0.4 and 0.6. It is due to the fact that batteries have low cycle-life, so we try to operate it within the stand-by condition [11]. Once the $S O C^{*}(t)$ is obtained, $P_{b a t}^{*}(t)$ is calculated as $(10)$. The PV power setpoint $P_{p v}^{*}(t)$ is calculated as (11) taking into account that $P_{b a t}^{*}(t)$ has been previously limited to between $P_{b a t-\max }$ and $P_{b a t-m i n}$.

$$
\begin{gathered}
\Delta P_{\text {max }}=R R_{\text {max }} \cdot \frac{T_{w}+T_{d}}{60} \cdot \frac{P_{\text {plant }}}{100} \\
\Delta P_{\text {min }}=R R_{\text {min }} \cdot \frac{T_{w}+T_{d}}{60} \cdot \frac{P_{\text {plant }}}{100} \\
S O C^{*}(t)=0.4+\frac{0.6-0.4}{P_{\text {plant }}} \cdot P_{\text {pv-meas }}(t)
\end{gathered}
$$




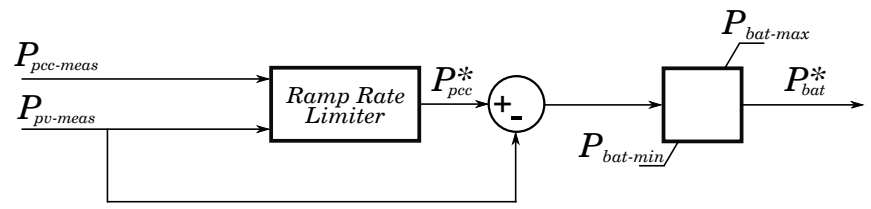

(a) Concept. This basic scheme is just to help understanding how it works

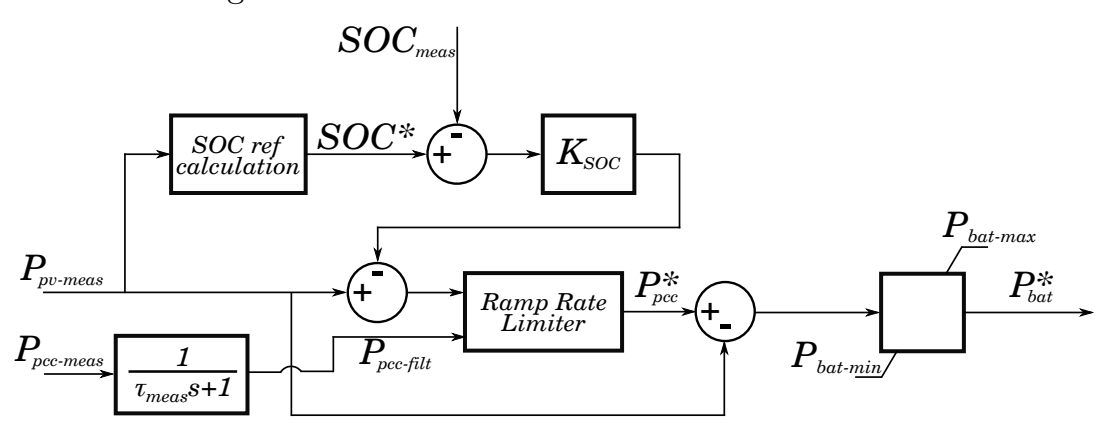

(b) Implemented strategy for battery setpoint computation (including the SOC control and the measurement filter to improve the performance)

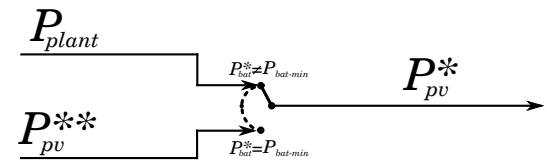

(c) Implemented strategy for PV setpoint computation. $P_{p v}^{*}$ calculation depends on the battery setpoint

Figure 5: Reference computation block - MPP mode

$P_{b a t}^{*}(t)= \begin{cases}P_{p c c-f i l t}\left(t-T_{w}\right)+\Delta P_{\text {max }}-P_{p v-\text { meas }}(t) & \text { if } P_{p v-\text { meas }}(t)-e(t)-P_{\text {pcc-meas }}\left(t-T_{w}\right)>\Delta P_{\text {max }} \\ P_{p c c-f i l t}\left(t-T_{w}\right)+\Delta P_{\text {min }}-P_{p v-\text { meas }}(t) & \text { if } P_{p v-\text { meas }}(t)-e(t)-P_{\text {pcc-meas }}\left(t-T_{w}\right)<\Delta P_{\text {min }} \\ -e(t) & \text { otherwise }\end{cases}$

$$
P_{p v}^{*}(t)= \begin{cases}P_{p c c-f i l t}\left(t-T_{w}\right)+\Delta P_{\text {max }}-P_{\text {bat-meas }}(t) & \text { if } P_{b a t}^{*}(t)=P_{b a t-m i n} \\ P_{\text {plant }} & \text { otherwise }\end{cases}
$$

$$
\text { Where } e(t)=K_{S O C} \cdot\left(S O C^{*}(t)-S O C_{\text {meas }}(t)\right)
$$




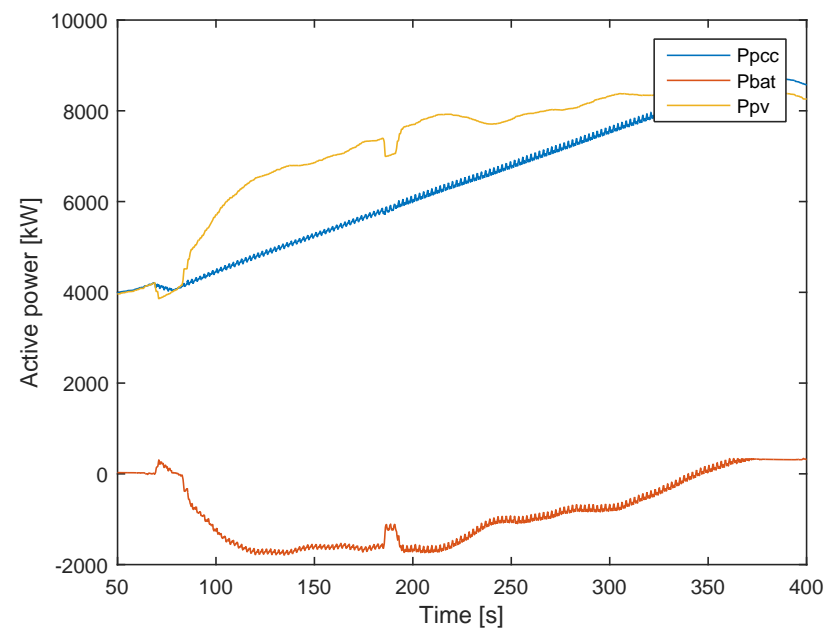

(a) Ramp limiter without filtering

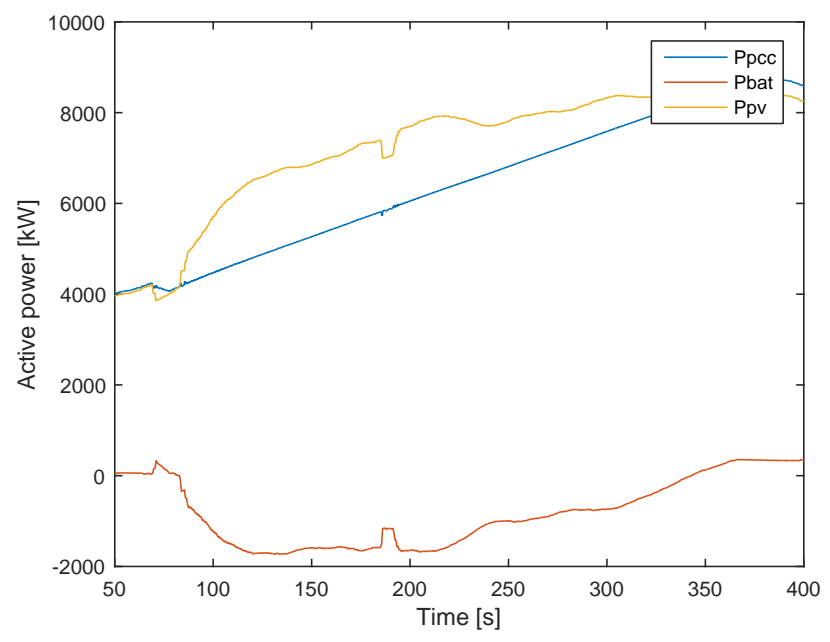

(b) Ramp limiter with filter

Figure 6: Example of ramp rate performance without and with filter. $T_{w}=2 \mathrm{~s}$. Total communication delay + battery response time $=50 \mathrm{~ms}\left(2.5 \%\right.$ of $\left.T_{w}\right)$. Total communication delay $+\mathrm{PV}$ plant response $(\mathrm{PV}$ controller + inverter dynamics $) \approx 1 \mathrm{~s}\left(50 \%\right.$ of $\left.T_{w}\right)$

247 Note that in [19], the $S O C^{*}$ is computed so that the energy flow through 248 the battery is reduced. But, it leads to operate the SOC from 0 to 1 p.u. 249 In contrast, our application tries to avoid operating it out from the stand-by 250 condition. 


\subsubsection{Curtailment Mode}

Considering the PPC is operating in MPP mode, once the TSO sets a curtailment setpoint $\left(P_{T S O}(t)<P_{\text {plant }}\right)$ the curtailment mode begins. $P_{p v-r}^{*}(t)$ (the TSO setpoint after applying the ramp limitation) is updated at the first iteration of the PPC according to (12). Then, at each PPC execution $P_{p v-r}^{*}(t)$ is updated following a ramp rate limitation according to (13). A saturation is applied as (14) in the case of ramp-up or as (15) in the case of ramp-down. Finally, $P_{p v}^{*}(t)$ and $P_{b a t}^{*}(t)$ are calculated as (16) and (17) respectively. In this way, the battery ensures that the active power at the $\mathrm{PCC}$ is the required by the ramp rate limitation. Adding an offset to the PV setpoint (see equation (16)) ensures the SOC control of the battery. The corresponding flow chart can be observed in Figure 7.

$$
\begin{gathered}
P_{p v-r}^{*}(t)=P_{\text {pcc-meas }}(t) \\
P_{p v-r}^{*}(t)= \begin{cases}P_{p v-r}^{*}\left(t-T_{s}\right)+\frac{R R_{\text {min }}}{100} \cdot \frac{P_{p l a n t}}{60} \cdot T_{s} & \text { if } P_{T S O}<P_{p v-r}^{*}\left(t-T_{s}\right) \\
P_{p v-r}^{*}\left(t-T_{s}\right)+\frac{R R_{\max }}{100} \cdot \frac{P_{p l a n t}}{60} \cdot T_{s} & \text { if } P_{T S O} \geq P_{p v-r}^{*}\left(t-T_{s}\right)\end{cases}
\end{gathered}
$$

Where $T_{s}$ is the sampling time of the PPC.

$$
\begin{array}{r}
P_{p v-r}^{*}(t)= \begin{cases}P_{p v-r}^{*}(t) & \text { if } P_{T S O} \geq P_{p v-r}^{*}(t) \\
P_{T S O} & \text { if } P_{T S O}<P_{p v-r}^{*}(t)\end{cases} \\
P_{p v-r}^{*}(t)= \begin{cases}P_{p v-r}^{*}(t) & \text { if } P_{T S O} \leq P_{p v-r}^{*}(t) \\
P_{T S O} & \text { if } P_{T S O}>P_{p v-r}^{*}(t)\end{cases} \\
P_{p v}^{*}(t)=P_{p v-r}^{*}(t)+\left(S O C^{*}(t)-S O C_{\text {meas }}(t)\right) \cdot K_{S O C} \\
P_{b a t}^{*}(t)=P_{p v-r}^{*}(t)-P_{p v-\text { meas }}(t)
\end{array}
$$

One can think that for a curtailment mode, $P_{b a t}^{*}(t)$ could be calculated as in the scheme of Figure 5(b). However, it would not result in a good performance in the case of $P_{p v-a v}(t)<P_{p v-r}^{*}(t)$ because the $P_{T S O}$ would not be reached. 


\subsubsection{Droop 1 mode}

During the MPP mode $\left(P_{T S O}=P_{\text {plant }}\right)$, a frequency deviation can occur. In this case the so-called Droop 1 mode is applied. In this mode, the droop setpoint, $P_{D}$, is calculated as (18) (this setpoint will remain constant until the frequency returns to the dead band, see Figure 7). The droop contribution $\Delta P$ is calculated at each computation loop of the PPC according to the curve of Figure 3(a). Then, the PV and battery setpoints are calculated as (19) and (20) respectively.

$$
\begin{gathered}
P_{D}=P_{p c c-\text { meas }} \\
P_{p v}^{*}(t)=P_{D}+\Delta P+\left(S O C^{*}(t)-S O C_{\text {meas }}(t)\right) \cdot K_{S O C} \\
P_{b a t}^{*}(t)=P_{p v}^{*}(t)-P_{p v-\text { meas }}(t)
\end{gathered}
$$

Once the frequency recover the normal values $\left(f_{\text {meas }}(t) \in\left[f_{2}, f_{3}\right]\right)$, it is desired to return to the MPP mode. Fast power changes can be avoided setting the curtailment mode despite $P_{T S O}=P_{\text {plant }}$, which will perform the ramp up event until the PV plant reaches the MPP and then the operation mode will change to MPP mode (see the transition conditions from Droop 1 to MPP modes in Figure 4(b)).

\subsubsection{Droop 2 mode}

If a frequency deviation occurs during a curtailment the reference computation block computes the Droop 2 mode. In this case $P_{D}$ is updated at each PPC execution as $(21)$, where $P_{p v-r}^{*}(t)$ is obtained by the same way than in the curtailment mode $\left(P_{p v-r}^{*}(t)\right.$ is the TSO setpoint after applying a ramp limitation). The PV and battery setpoints are calculated again considering the droop curve, the updated $P_{D}$ and equations (19) and (20). When the droop mode ends, $P_{p v-r}^{*}(t)$ is updated to $P_{p c c-m e a s}(t)$ and curtailment mode is applied again to go from mode Droop 2 to mode curtailment with ramp transition avoiding fast changes.

$$
P_{D}(t)=P_{p v-r}^{*}(t)
$$

\subsection{Summary}

To improve the readability of section 5, a flow diagram of the control solution is included in Figure 7 


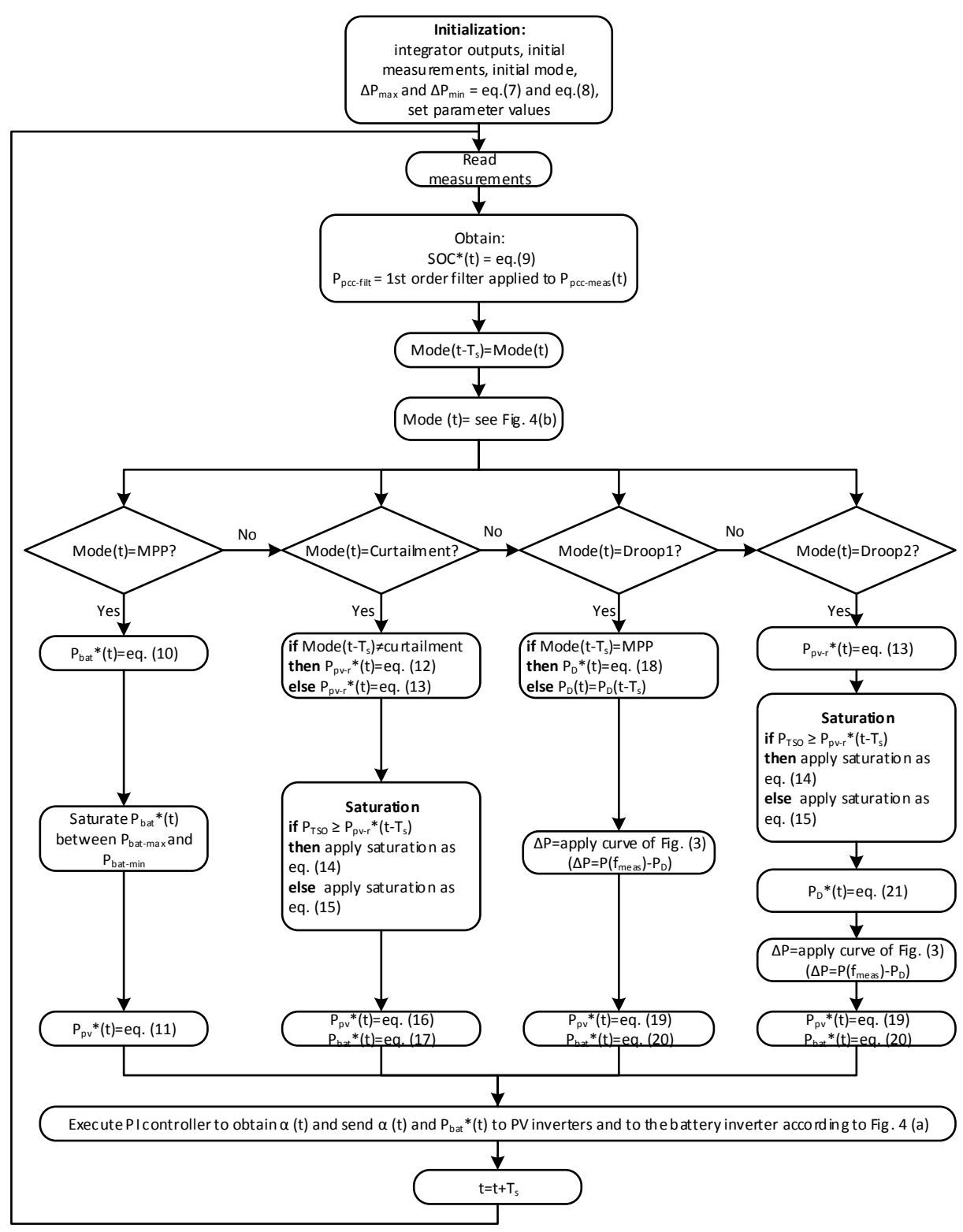

Figure 7: Flow diagram of the control solution

\section{Results}

The characteristics of the power plant are shown in Table 1.

The data of $P_{p v-a v}$ has been obtained thanks to the NREL database [20]. 
Table 1: Parameters used in the simulation

\begin{tabular}{|ll|ll|}
\hline Parameter & Value & Parameter & Value \\
\hline$P_{\text {plant }}$ & $9.4 \mathrm{MW}$ & $\tau_{p v}$ & $100 \mathrm{~ms}$ \\
$P_{\text {bat-max }}$ & $1 \mathrm{MW}$ & $\tau_{\text {bat }}$ & $10 \mathrm{~ms}$ \\
$P_{\text {bat-min }}$ & $-1 \mathrm{MW}$ & $\eta_{\text {bat }}$ & 0.95 \\
$C_{\text {bat-nom }}$ & $167 \mathrm{kWh}$ & $\tau_{\text {com }}$ & $20 \mathrm{~ms}$ \\
$T_{w}$ & $2 \mathrm{~s}$ & $T_{s}$ & $100 \mathrm{~ms}$ \\
$R R_{\text {max }}$ & $10 \%$ & $R R_{\text {min }}$ & $-10 \%$ \\
$K_{p-p v}$ & 0.05 & $K_{i-p v}$ & 1 \\
$K_{w-p v}$ & 10 & $K_{S O C}$ & 1880 \\
$\tau_{\text {meas }}$ & $1 \mathrm{~s}$ & $f_{\min }$ & $47 \mathrm{~Hz}$ \\
$f_{1}$ & $49.5 \mathrm{~Hz}$ & $f_{2}$ & $49.8 \mathrm{~Hz}$ \\
$f_{n}$ & $50 \mathrm{~Hz}$ & $f_{3}$ & $50.2 \mathrm{~Hz}$ \\
$f_{4}$ & $52 \mathrm{~Hz}$ & $f_{\max }$ & $53 \mathrm{~Hz}$ \\
\hline
\end{tabular}

First, second by second irradiance data (from 1 Apr. of 2011 to 13 May of 2011 in Oahu, Hawaii) has been obtained and then, based on the model of [16], the available PV power has been calculated. According to [16], the PV power output can be obtained applying a first order filter to the irradiance data and scaling the result by a gain of $\frac{P_{\text {plant }}}{1000}$. The filter time constant is $\frac{\sqrt{S}}{2 \pi \cdot 0.02}$, where $\mathrm{S}$ is the area of the PV plant in ha. For this work, $S=52 \mathrm{Ha}$ is chosen.

\subsection{MPP mode}

Figure 8 shows a complete day operating under MPP mode. In general, it can be observed that the battery is only used in presence of high solar energy variability. The rest of the time, just the SOC control contribution is applied to the battery. The zoomed area shows the PV power and the PCC power. It can be observed that the ramp rate limitation is fulfilled. As explained previously, the SOC setpoint is computed depending on the PV power generated. It is shown on the bottom plot of Figure 8 .

In [9], it is suggested to evaluate ramp rate compliance by taking a sample of the ramp rate each two seconds and calculating the \% of ramp rate excursions out of the limits (for $10 \%$ ramp rate limit, a breach is considered to be at $11 \%$ ). The time window for calculating the ramp rate is 2 seconds. By the methodology presented in this paper, the ramp rate compliance is $98 \%$, while without battery compliance drops to $91 \%$ (calculations exclude 
night-time). It is worth noting that the battery sizing is out of the scope of this paper. Larger battery of $7 \mathrm{MW}$ and $900 \mathrm{kWh}$ has also been simulated. In this case the ramp rate compliance increases up to $99.3 \%$ higher than the $98.5 \%$ required according to [9]. Reaching the $100 \%$ of the ramp rate compliance will rarely occur as the controller is corrective (first detects the ramp fault and then reacts).

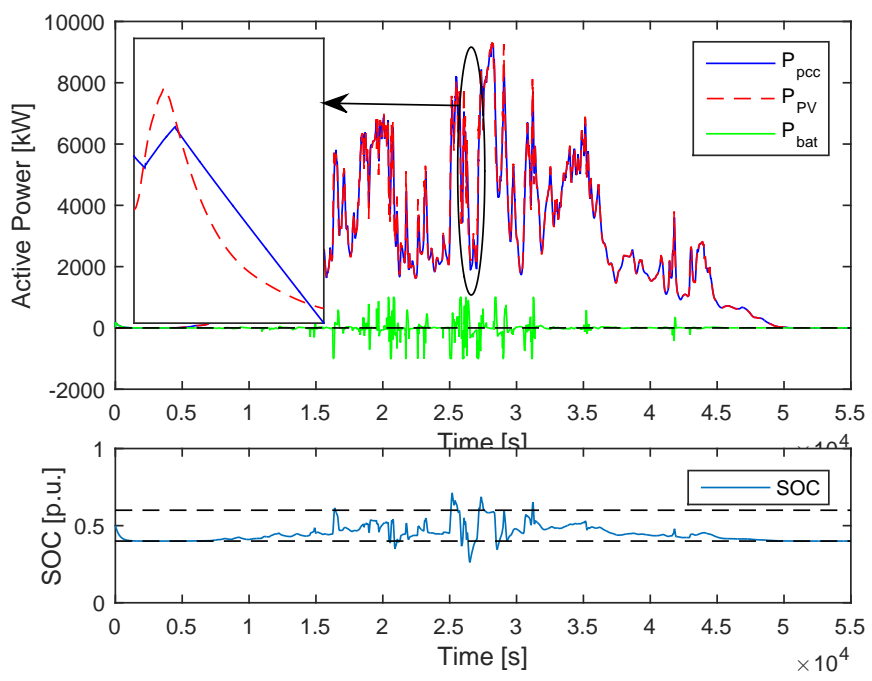

Figure 8: Simulation of a complete day under MPP mode. Top plot: PCC (blue), PV (red), and battery (green) active power. Bottom plot: SOC (blue) and 0.4-0.6 p.u. range (dashed)

\section{2. $S O C$ control}

The SOC control strategy is evaluated by means of how the battery operation could affect its lifetime. Determining the ageing of the battery is out of the scope of this paper. However, it is known that the desirable SOC level to operate the battery is between 0.4 and $0.6 \mathrm{p} . \mathrm{u}$, defined as standby condition [11]. In addition, the amount of power flowing through the battery indicates its usage and hence, it also affects the battery lifetime. These two parameters are compared here between the proposed SOC strategy and a constant SOC setpoint strategy.

Figure 9 compares the SOC control strategies: in blue considering constant SOC setpoint and in red the proposed strategy according to equation (9). Forty three consecutive days have been simulated. Figure 9 shows the 
first 7 days where the night time has been reduced due to the limitation of computational time. To compare these strategies, MPP mode is applied where the PV power is shown in the top plot. As it can be observed, the time of 'out of the standby operation' reduces compared to a constant SOC setpoint.
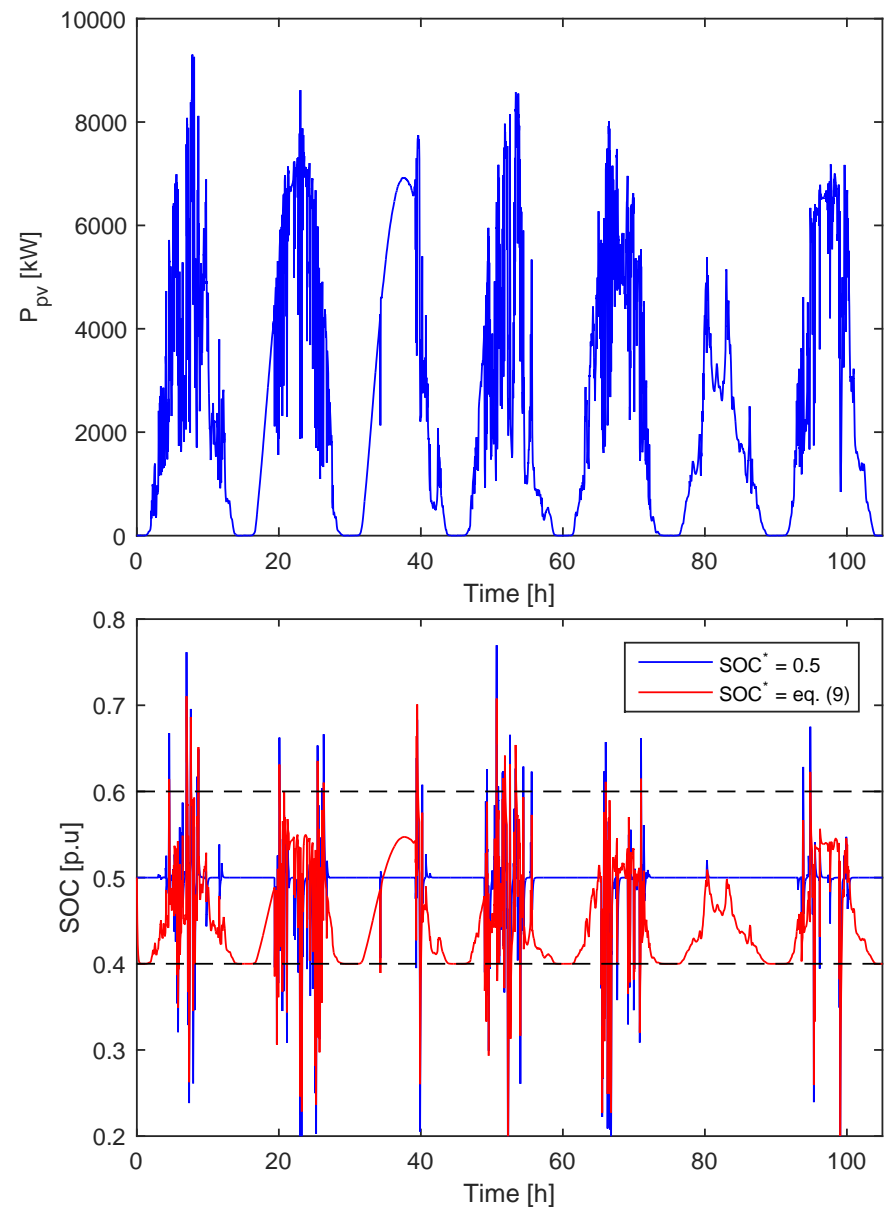

Figure 9: Comparison of SOC control strategies (MPP mode). Top plot: PV power profile. Bottom plot: $\mathrm{SOC}$ for both strategies, $S O C^{*}=0.5$ in blue and $S O C^{*}=$ eq. (9) in red.

The results of the 43 days are shown in Tables 2 and 3. Table 2 shows the time in which the battery is operating 'out from the standby' condition. Generally, this time is reduced by applying the proposed strategy. In addition, it can be observed that the higher the deviation from the standby 
condition, the higher is the time reduction. So, we can conclude that the SOC for the proposed strategy is closer to the standby condition.

Table 2: Time [min] during which the SOC is out of the standby condition (43 days of simulation)

\begin{tabular}{|l|cccc|}
\hline & $S O C \in$ & $S O C \in$ & $S O C \in$ & $S O C \in$ \\
& {$[0,0.4) \cup(0.6,1]$} & {$[0,0.3) \cup(0.7,1]$} & {$[0,0.2) \cup(0.8,1]$} & {$[0,0.1) \cup(0.9,1]$} \\
\hline$S O C^{*}=0.5$ & 1316 & 315 & 40 & 3 \\
$S O C^{*}=$ eq. (9) & 1290 & 235 & 18 & 0 \\
\hline \% of reduction & 2.0 & 25.3 & 54.6 & 100 \\
\hline
\end{tabular}

Table 3 shows the total energy flowing through the battery during the 43 simulated days. It can be observed that for high variability days, the total energy flowing through the battery is reduced, on average, by $2.8 \%$ with the proposed strategy. In contrast during the medium and low variability days, the total energy flowing through the battery with the proposed strategy is greater than considering a constant SOC setpoint. The high difference in low variability days is due to the fact that, while the proposed SOC control strategy performs one cycle during these days, the constant SOC strategy does not use the battery (see SOC of days 3 and 6 in Figure 9).

Table 3: Total (in + out) energy flowing through the battery [kWh] (43 days of simulation)

\begin{tabular}{|c|ccc|}
\hline & $\begin{array}{c}\text { High variability } \\
(14 \text { days })\end{array}$ & $\begin{array}{c}\text { Medium variability } \\
(14 \text { days })\end{array}$ & $\begin{array}{c}\text { Low variability } \\
(15 \text { days })\end{array}$ \\
\hline $\mathrm{SOC}=0.5$ & 24202 & 10100 & 2772.1 \\
$\mathrm{SOC}=$ eq. $(9)$ & 23525 & 10199 & 3532.9 \\
\hline \% of reduction & 2.8 & -1.0 & -27.4 \\
\hline
\end{tabular}

To sum up, the proposed SOC control strategy is better for days with high variability of solar generation as the SOC is operated closed the standby condition and lower energy flow is required. But for the same reason, for sunny days, the constant SOC strategy improves operation of the battery. The election of which strategy suits better for a power plant will depend on the location and the climate. Also, it could be elected by de plant operator according to the expected performance in the future days. In this case, precise information would not be required, just the type of weather as sunny, partial cloudy or full overcast for the next days. 
In addition, the ramp rate compliance has been analysed for the 43 simulated days (Figure 10). Considering the whole simulation period, without the battery the ramp rate compliance reaches $88.9 \%$ while with the battery it reaches up to $97 \%$ (night time is excluded). The proposed control with a larger battery would have the potential to comply during $99 \%$ of the time. For this latter calculation, we used a battery of $7 \mathrm{MW}$ and $900 \mathrm{kWh}$. The corresponding ramp rate distribution is shown in Figure 10(a) where it can be observed that most of the ramp rate faults without battery are moved to the $10 \%$ ramp rate limit when the battery is installed. Figure 10(b) shows the ramp rate compliance histogram for three different scenarios: i) without battery ii) with the simulated $1 \mathrm{MW}$ battery and iii) with $7 \mathrm{MW}$ battery. It is shown that with a properly sized battery the ramp rate specified by the grid code is accomplished.

\subsection{Power curtailment}

The power curtailment performance is shown in Figure 11. The PV power follows a ramp until reaching the setpoint. The battery just performs its SOC control. During the short period when there is not enough available PV power, the battery helps to achieve the setpoint. Once the available PV power is again greater than the TSO setpoint, a small transient that is due to the PV PI controller can be observed. This controller saturates its output at the nominal PV plant power (see the black dotted line). So, once the available power is greater than the setpoint, the output of the controller starts to decrease. However, at the beginning this reduction has no effect because the available active power is still smaller than the PI output. Nevertheless, the battery also contributes following the TSO setpoint during this transient. When the power curtailment ends, a ramp-up limitation is performed until the available power reaches its MPP. We know the MPP is reached because the PI controller output is saturated at the MPP.

\subsection{Frequency droop}

Figure 12 show the previous performance but during the curtailment, a droop event occurs for up and for down frequency event (Figures 12(a) and 12(b) respectively). In Figure 12(a), it is observed how once the frequency increases, the output power automatically reduces adding an offset $\Delta P$ to the TSO ramp limited setpoint. At the same time that the droop and curtailment operation is performed, the SOC control is applied. It can be observed in the bottom plot, where the $S O C^{*}$ is calculated as (9). In Figure 12(b) the down 


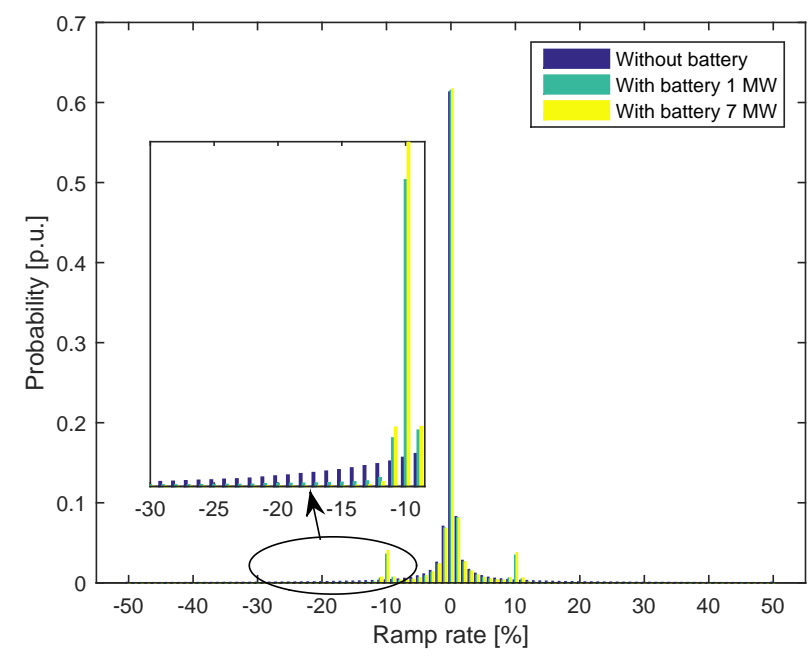

(a) Normalized distribution of the ramp rate

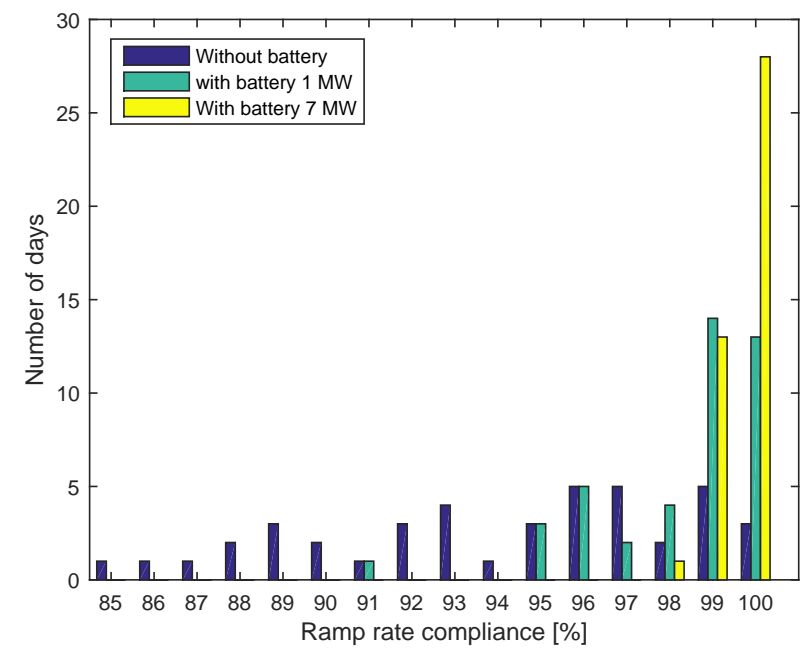

(b) Histogram of the ramp rate compliance per days for different scenarios

Figure 10: Ramp rate performance during 43 days for different scenarios: i) without battery, ii) with battery $1 \mathrm{MW}$ and iii) with battery $7 \mathrm{MW}$

frequency droop curve is shown. It is observed how the battery performs the SOC control and, when there is a lack of PV power, it supports the power plant by injecting additional active power.

Finally, Figure 13 depicts the good performance of droop operation when 


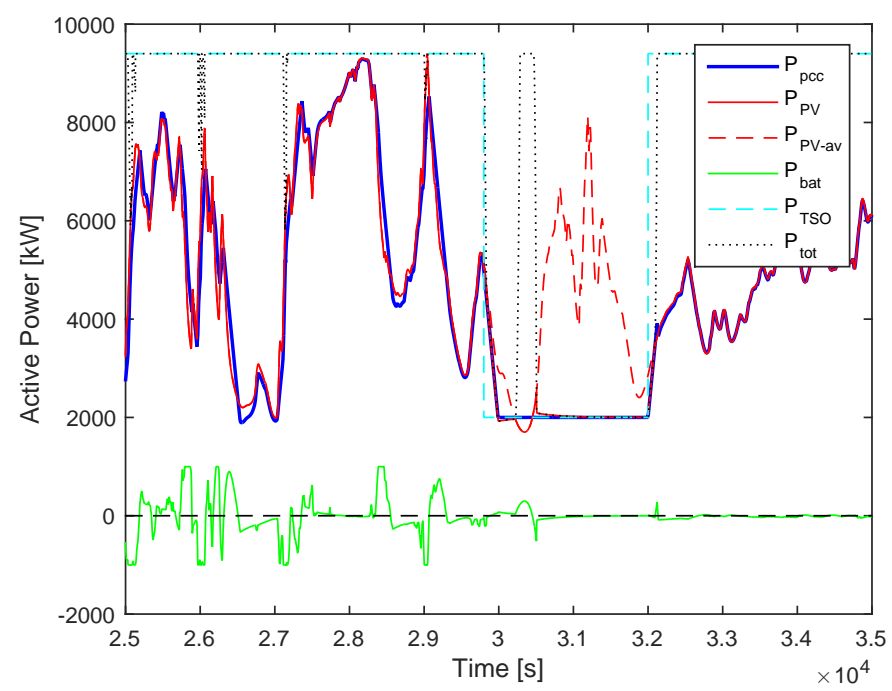

Figure 11: PV, battery and PCC active power response after curtailment. Curtailment is set at $2 \mathrm{MW}$ between $29800 \mathrm{~s}$ and $32000 \mathrm{~s}$ (blue dashed line).

the PV plant is operating at the MPP mode. It is shown how the droop contribution is applied instantaneously and, when the frequency goes back to the dead band, the PV plant returns to the MPP in a smooth way (ramped).

\section{Conclusion}

In this paper, a power plant controller to fulfill grid code requirements in hybrid PV-storage power plants has been presented. In particular, power curtailment, frequency droop and ramp rate limitation restrictions have been studied with satisfactory results.

The traditional SOC control for low cycle-life storage systems $\left(S O C^{*}=\right.$ 0.5 ) has been modified so that the $S O C^{*}$ follows the PV power generated, where the result shows that it keeps the battery less stressed during days with high variability of solar production. In addition, the controller permits SOC control during curtailment and frequency droop events. In case of having a lack of PV power to reach the curtailment or droop setpoints, the controller uses the battery to fulfill these requirements, which improves the performance in comparison with PV plants that are not equipped with storage systems.

The ramp rate control has been performed taking into account a strong restriction (time window of two seconds). With small time windows, it has 
been observed that power oscillations could occur. To deal with this problem, a filter has been included to the typical ramp rate controller. The result is that the power ripple caused by delays during ramp event in the MPP mode has been suppressed.

It has been shown that the 2 -second ramp rate compliance may be fulfilled by the proposed controller. For that purpose, a properly sized battery is required.

\section{Acknowledgement}

The research leading to these results has received support of the Secretaria d'Universitats i Recerca del Departament d'Economia i Coneixement de la Generalitat de Catalunya and has been co-funded by the European Social Fund. The research leading to these results has received funding from the European Union Seventh Framework Program FP7-ICT-2013-11 under grant agreement 619610 (Smart Rural Grid). The authors would like to thank the National Renewable Energy Laboratory (NREL) for providing second by second irradiance data.

\section{Appendix A. Working principle of the measurement filter for im- proving the ramp rate performance}

Let us consider the ramp rate control scheme of Figure 5(a) and the same scheme but filtering the $P_{p c c-m e a s}(t)$, see Figure 5(b). Now, we apply a PV power step and analyse the response of the system in Figures A.14 and A.15 (the response under a real PV profile can be observed above in Figure 6).

Figure A.14 shows the performance according to the control scheme without the proposed filter. In this case, once the PV power drops, the controller (executed each $T_{s}=100 \mathrm{~ms}$ ) detects the ramp event by comparing the actual PV measurement (red) and the previous PCC measurement $P_{p c c-m e a s\left(t-T_{w}\right)}$ (dashed black) and computes the required setpoint to the battery. Due to the communication delays and plant dynamics, the setpoint is not applied instantaneously. So, The PCC power (blue) drops transiently until the battery reacts. This will be a problem after $T_{w}$ seconds as the measured power $P_{\text {pcc-meas }}\left(t-T_{w}\right)$ will drop despite the PV power remains constant (see the second oscillation in zoomed area). This fact, will be understood as an upramp event and a power oscillation will occur. It happens each $T_{w}$ seconds. So, the result is that PCC power presents power oscillations of a period $T_{w}$. 
Figure A.15 shows the performance according to the proposed control scheme with filter. As it can be observed, at the beginning of the ramp event the system behaves exactly in the same way. After $T_{w}$ seconds, the measured power $P_{\text {pcc-meas }}\left(t-T_{w}\right)$ (not shown in the plot) drops in the same way. But in this control scheme, the controller uses the power filtered $\left(P_{p c c-f i l t}\left(t-T_{w}\right)\right.$, black dashed). So, the initial transient in $P_{p c c-m e a s}$ is not observed by the controller and the power oscillations during the ramp event are mitigated. Note that as the controlled variable $\left(\Delta P_{\max }\right.$ and $\left.\Delta P_{\min }\right)$ depends on a time window and the filter adds a delay, it has to be taken into account in the ramp rate calculation as explained before.

\section{References}

[1] Medium-Term Market Report Executive Summary 2014. Market Analysis and Forecasts to 2020, IEA, International Energy Agency.

[2] R. Ferroukhi, D. Gielen, G. Kieffer, M. Taylor, D. Nagpal, A. Khalid, REthinking Energy, 2014, IRENA, International Renewable Energy Agency, 2014.

[3] J. M. Ivan Pineda, Sarah Azau, J. Wilkes, Wind in power. 2013 European statistics, EWEA, European Wind Energy Association, 2014.

[4] H. Berndt, M. Hermann, H. D. Kreye, R. Reinisch, U. Scherer, J. Vanzetta, Transmission code 2007 - Network and system rules of the German transmission system operators, Verband der Netzbetreiber - VDN - e.V. beim VDEW, 2007.

[5] Grid connection code for renewable power plants (RPPs) connected to the electricity transmission system (TS) or the distribution system (DS) in South Africa, 2012.

[6] Technical transmission grid code of the Romanian power system, Romanian Power Grid Company TRANSELECTRICA S.A., 2004.

[7] Minimum technical requirements for interconnection of photovoltaic (PV) facilities, Puerto Rico Electric Power Authority. PREPA, 2012.

[8] B. Noone, PV integration on Australian distribution networks. Literature review, The Australian PV Association, 2013. 
[9] C. Koch-Ciobotaru, A. S. de Ibarra, E. Martinez-Laserna, D. I. Stroe, M. Swierczynski, P. Rodriguez, Second life battery energy storage system for enhancing renewable energy grid integration, in: 2015 IEEE Energy Conversion Congress and Exposition (ECCE), 2015, pp. 78-84. doi:10.1109/ECCE.2015.7309672.

[10] E. Bullich-Massagué, R. Ferrer-San-José, M. Aragüés-Peñalba, L. Serrano-Salamanca, C. Pacheco-Navas, O. Gomis-Bellmunt, Power plant control in large-scale photovoltaic plants: design, implementation and validation in a $9.4 \mathrm{mw}$ photovoltaic plant, IET Renewable Power Generation 10 (1) (2016) 50-62. doi:10.1049/iet-rpg.2015.0113.

[11] R. van Haaren, M. Morjaria, V. Fthenakis, An energy storage algorithm for ramp rate control of utility scale pv (photovoltaics) plants, Energy 91 (2015) 894 - 902. doi:http://dx.doi.org/10.1016/j.energy.2015.08.081.

[12] M. J. E. Alam, K. M. Muttaqi, D. Sutanto, A novel approach for ramprate control of solar pv using energy storage to mitigate output fluctuations caused by cloud passing, IEEE Transactions on Energy Conversion 29 (2) (2014) 507-518. doi:10.1109/TEC.2014.2304951.

[13] V. Salehi, B. Radibratovic, Ramp rate control of photovoltaic power plant output using energy storage devices, in: PES General Meeting - Conference Exposition, 2014 IEEE, 2014, pp. 1-5. doi:10.1109/PESGM.2014.6938985.

[14] K. Prompinit, S. Khomfoi, Ramp rate consideration of a bess using active power control for pv generation, in: Electrical Machines and Systems (ICEMS), 2015 18th International Conference on, 2015, pp. 16761680. doi:10.1109/ICEMS.2015.7385310.

[15] S. Abdollahy, A. Mammoli, F. Cheng, A. Ellis, J. Johnson, Distributed compensation of a large intermittent energy resource in a distribution feeder, in: Innovative Smart Grid Technologies (ISGT), 2013 IEEE PES, 2013, pp. 1-6. doi:10.1109/ISGT.2013.6497911.

[16] J. Marcos, L. Marroyo, E. Lorenzo, D. Alvira, , E. Izco, From irradiance to output power fluctuations: the pv plant as a low pass filter, Progress in Photovoltaics: Research and Applications 19 (1) (2011) 505-510. 
[17] J. Marcos, I. de la Parra, M. Garca, L. Marroyo, Control strategies to smooth short-term power fluctuations in large photovoltaic plants using battery storage systems, Energies 7 (10) (2014) 6593. doi:10.3390/en7106593. URL http://www.mdpi.com/1996-1073/7/10/6593

[18] A. Cabrera-Tobar, E. Bullich-Massagué, M. Aragüés-Peñalba, O. Gomis-Bellmunt, Review of advanced grid requirements for the integration of large scale photovoltaic power plants in the transmission system, Renewable and Sustainable Energy Reviews 62 (2016) 971 - 987. doi:http://dx.doi.org/10.1016/j.rser.2016.05.044.

URL http://www.sciencedirect.com/science/article/pii/ S136403211630154X

[19] I. de la Parra, J. Marcos, M. García, L. Marroyo, Control strategies to use the minimum energy storage requirement for $\mathrm{pv}$ power ramp-rate control, Solar Energy 111 (2015) 332 - 343. doi:http://dx.doi.org/10.1016/j.solener.2014.10.038.

[20] M. Sengupta, A. Andreas, (2010) oahu solar measurement grid (1-year archive), nrel report no. da-5500-56506.

URL http://dx.doi.org/10.5439/1052451 

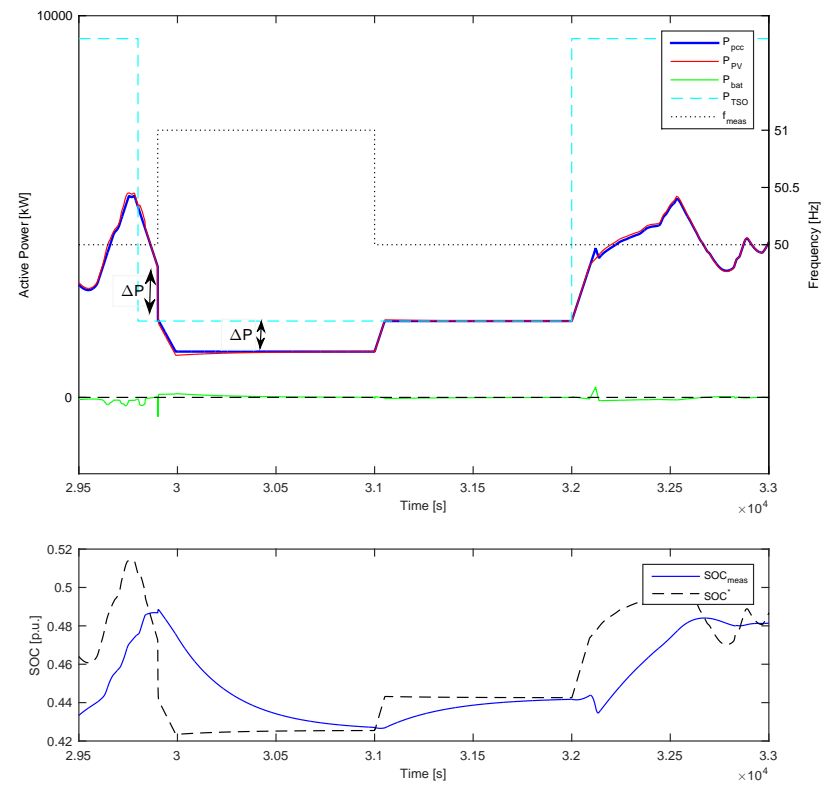

(a) Up frequency event. Enough PV power is available and no battery support is required.
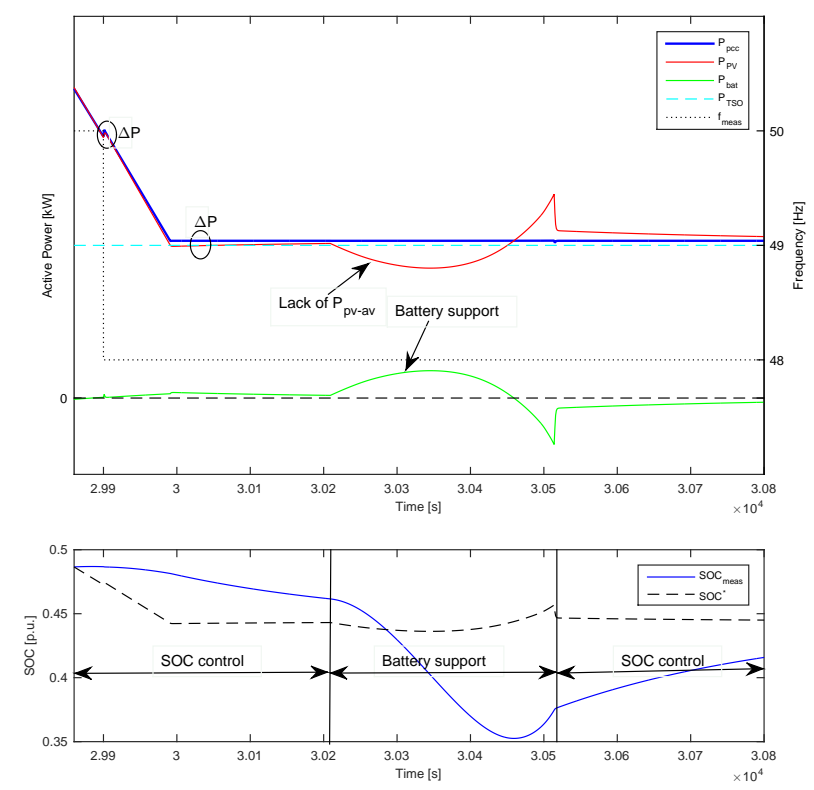

(b) Down frequency event. Lack of PV power available and battery provides support to comply the setpoint.

Figure 12: Frequency droop response during curtailment. PCC, PV and battery active power and SOC control analysis. 


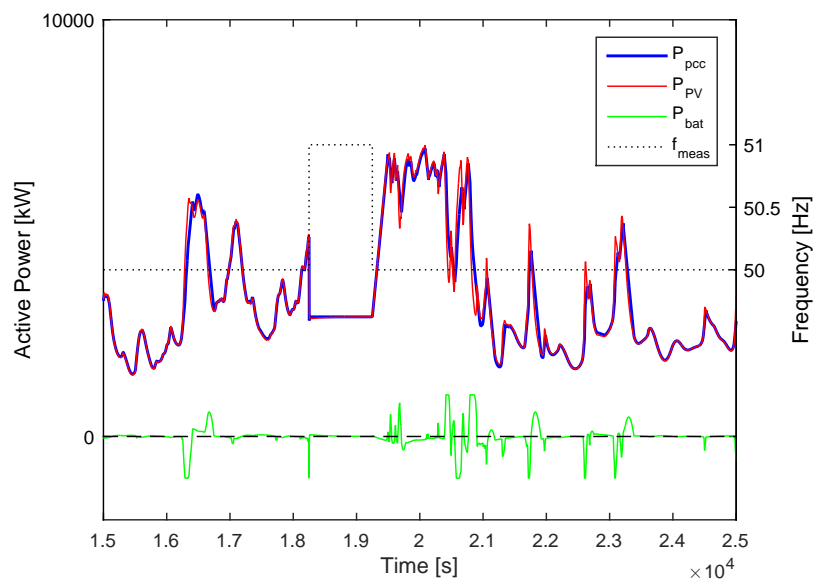

Figure 13: Frequency droop response during MPP operation mode. PCC, PV and battery active power analysis. In this case, there is enough PV power. So, no battery support is required.

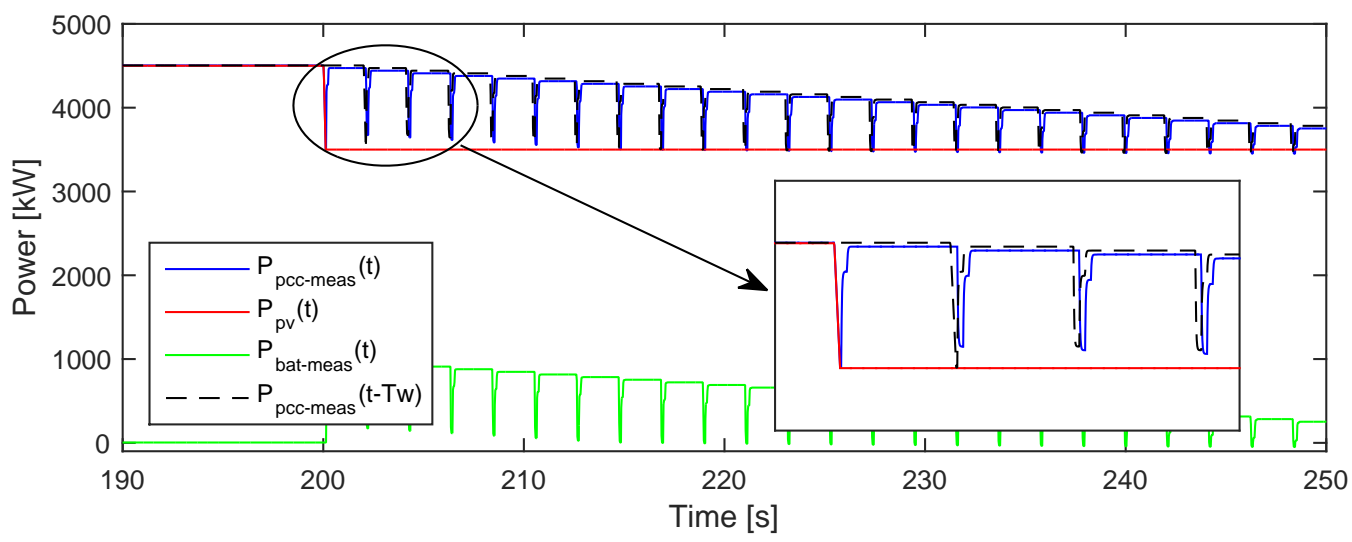

Figure A.14: Ramp rate response after a 1 MW PV power step at second 200. Conventional method without the filter 


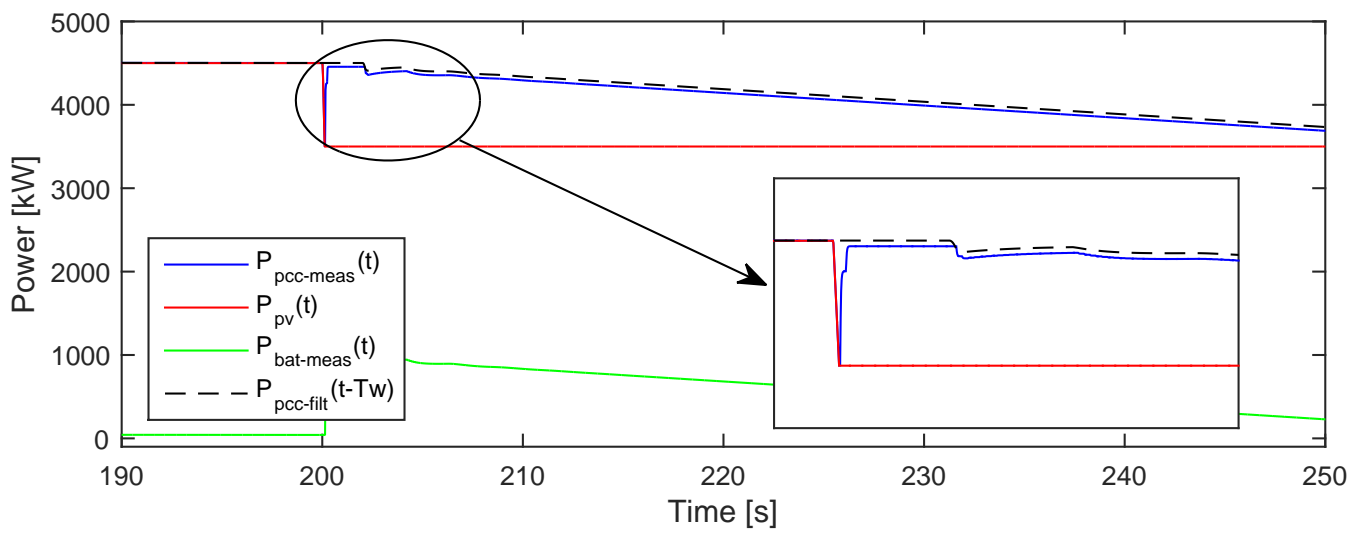

Figure A.15: Ramp rate response after a 1 MW PV power step at second 200. Proposed method: filter applied 